\title{
Choice Overload in the Grocery Setting: Results from a Laboratory Experiment
}

\author{
Benedetta Grandi ${ }^{1} \&$ Maria Grazia Cardinali ${ }^{1}$ \\ ${ }^{1}$ Department of Economics and Management, University of Parma, Parma, Italy \\ Correspondence: Benedetta Grandi, Department of Economics and Management, University of Parma, via \\ Kennedy 6, 43123 Parma, Italy.
}

Received: September 29, 2020

Accepted: November 23, 2020 Online Published: December 28, 2020

doi:10.5539/ibr.v14n1p94

URL: https://doi.org/10.5539/ibr.v14n1p94

\begin{abstract}
One of the most basic strategic decisions a retailer must take involves determining the product assortment to offer inside the store. Despite the importance of the topic, there are two opposite strands of literature that have come up with completely different points of view. To summarize them, the first one states that the more choices, the better, while the second one states that more choices lead to weaker preferences and lower levels of satisfaction. Furthermore, the majority of studies conducted so far have focused their attention on collecting self-report measures. However, it has been argued thet self-report measures, interviews and questionnaires may have strong biases. Specifically, they are a product of psychological, sociological, linguistic, experiential and contextual variables, which may have little to do with the construct of interest. Thus, the present work intends to enrich the extant literature about the effect of 'choice overload' on customer satisfaction and behavior inside the store by analyzing both cognitive and unconscious responses. In order to confirm our hypothesis, an experiment, involving 171 participants, was conducted in a laboratory supermarket in Milan to test the reactions in front of a regular pastry display and a display characterized by fewer options.
\end{abstract}

Keywords: choice overload, assortment reduction, eye-tracking, satisfaction, laboratory setting

\section{Introduction}

One of the most basic strategic decisions a retailer must make involves determining the product assortment to offer. By making appropriate trade-offs with respect to variety, depth, and service levels, retailers hope to satisfy customers' needs by providing the right merchandise in the right store at the right time (Mantrala et al., 2009).

If the retailer fails to provide the expected assortment, customers defect, causing losses in both current and future sales (Mantrala et al., 2009). Furthermore, levels of satisfaction with the choice can affect retailers' performances, in terms of satisfaction to the store and loyalty (Dennis \& Martenson, 2007).

Despite the importance of the topic, there are two opposite strands of literature that have come up with completely different points of view related to effects of the numbers of options available on satisfaction and purchasing behavior.

The very early literature about the effects of number of options available on satisfaction with the choice, motivation to choose and emotions aroused state that the more choices, the better. This assumption is based on the classic economic theory. In fact, it argues that large assortments can better match individuals' characteristics, they can allow customers to maintain a certain flexibility when taking a decision and, finally, they create a perception of freedom of choice (Iyengar \& Lepper, 2000, 2006; Scheibehenne et al., 2009). This is consistent with the strategies developed by Retailers: they offer large assortments in all categories in order to meet customers' needs.

However, at the same time another stream of literature has come up with a completely different point of view. In particular, it is based on the assumption that large assortments, and in general more choices, increase individuals' cognitive resources and efforts required in order to evaluate the attractiveness and the value of each option. Consequently, more choices lead to weaker preferences and lower levels of satisfaction (Fasolo et al., 2007; Gourville \& Soman, 2005; Scheibehenne et al., 2010). Embracing this second strand of literature, the present work intends to reinforce the theory according to which 'less is more' and to fill a gap in the extant literature related to the methodology used, the number of alternatives proposed and the setting where the experiment takes 
place. As a proof, the studies conducted so far have focused their attention on analyzing conscious responses. Participants in the majority of the studies conducted were asked to make a choice in front of two different assortments (one large and one with fewer options) and consequently they were asked to indicate their level of satisfaction with the choice, the attractiveness of the option selected, the perceived ease and freedom of choice (Chernev, 2003a, 2003b). However, several papers have stated and demonstrated that self-report measures, interviews and questionnaires, may have strong biases. Furthermore, the present study wants to enrich the extant literature by considering more options in the experiment and testing the effects of choice overload in a realistic setting.

\section{Literature Review}

The term choice overload is generally used in reference to 'a scenario in which the complexity of the decision problem faced by an individual exceeds the individual's cognitive resources' (Simon, 1955; Iyengar \& Lepper, 2000). In this research, our focus is on the aspect of overchoice according to which the decision complexity is caused by a great number of available options. In fact, studies show that 'the selection, evaluation, and integration of information are all clearly affected by the available number of options' (Iyengar \& Lepper, 2000). This suggests that, as the complexity of making choices increases, people tend to simplify their decision-making processes by relying on simple heuristics (Iyengar \& Lepper, 2000).

Choice overload is a complex concept and it cannot be directly observed, since it is a mental construct describing the subjective state of the decision maker (Chernev et al., 2015). It can be expressed in terms of decision confidence, satisfaction regret and behaviors (assortment choice, options selection). In the extant literature, among all the factors identified, task factors were found to be antecedents of choice overload. In particular, task factors describe the general structural characteristics of the decision problem, including number of alternatives, number of attributes describing each option, time constraints, decision accountability, and information presentation mode (Chernev et al., 2015).

Considering the role of the number of alternatives on customers' choice and satisfaction, most of the late studies support the hypothesis according to which fewer options lead to better results. According to them, in front of large assortments individuals need to put extra effort in order to evaluate all the alternatives in choosing between a great number of alternatives and it is almost impossible to make an exhaustive comparison between all of them (Iyengar \& Lepper, 2000, 2006; Scheibehenne et al., 2010). It is not always true that individuals have formed preferences when they go shopping. Most of the time individuals make choices in areas where they do not have expertise and they have to process the information available at the time of the choice. Thus, the selection would be easier in front of a smaller assortment rather than a larger one (Chernev, 2003b; Fasolo et al., 2007). Recent empirical studies have demonstrated that large assortments lead to negative consequences, such as dissatisfaction, regret, disappointment with the choice and decreased motivation to make a choice (Scheibehenne et al., 2009). Moreover, other research suggest that in front of a great number of options available at the moment of the choice shoppers tend to consider fewer items and to process a smaller part of the overall information available (Iyengar \& Lepper, 2006). Furthermore, individuals who face large assortment sometimes defer the decision or decide not to choose (Iyengar \& Lepper, 2006). Finally, research has shown that as the attractiveness of alternatives rises, individuals experience conflict and as a result tend to defer decision, search for new alternatives, choose the default option, or simply opt not to choose (Iyengar \& Lepper, 2000). An extensive array of options at first seems highly appealing to consumers, but it can reduce their subsequent motivation to purchase the product and the satisfaction related to the choice.

Retailers have based their strategies on the classic economic and choice theory, according to which more options available can better match individuals' preferences and needs. Thus, retailers have often taken it for granted that if some choice is good, more choice will be even better. However, based on the results of the overchoice theory, individuals might experience negative and uncomfortable situations while shopping. In addition, low levels of satisfaction with the choice affect retailers' performances, in terms of satisfaction to the store and loyalty (Martenson, 2007). Therefore, giving strong evidence about the effects of assortment variety is fundamental for retailers that want to meet their customers' needs. In doing so, detecting both rational and unconscious variables can give a more complete picture of the phenomenon. However, studies developed so far have mainly analyzed the consequences through a rational perspective by asking participant to comment their choice in front of a given selection of items. However, this is not always the best choice. Specifically, both theory and research indicate that self-report responses are a product of psychological, sociological, linguistic, experiential and contextual variables, which may have little to do with the construct of interest (Harrison et al., 1996). Because of influences other than item content, it has been pointed out that it is never clear precisely what is being measured (Crowne \& Marlowe, 2011). Furthermore, for what concern interviews, Nunkoosing, 2005 stated that the authority of the 
interviewer as a seeker of knowledge and methodological expertise is a critical issue that cannot be excluded from interviews, as it might have an impact of the interview outcome. One of the main biases that we can encounter are 'social desirability' biases. It refers to the 'tendency to answer selfreport items in such a way as to deliberately or unconsciously represent oneself in a favourable light' ("Self-Report Measures," 2011). Thus, using tools that may overcome 'conscious responses' may be an effective way to assess customers' behaviours. According to the authors' knowledge, few studies have tried to detect unconscious responses and behaviours of the customers using tools like eye tracking in a realistic setting. This is also consistent with the fact that most of the choices are made mindlessly and since customers are not always aware of the processes they adopt while shopping, asking them to point out the reasons of their choices may be misleading (Wansink, 2012).

However, understanding the unconscious mechanism may be useful since it has been demonstrated that many food-related decisions occur in distracting everyday environments that may lead to relatively mindless choices (Wansink, 2012). Very often people are not able or willing to exert self-control (Salmon et al., 2015; Wansink \& Sobal, 2007). Recently, it has become clear that the majority of our choices and actions are regulated by nonconscious and nonintentional processes (Papies, 2016). Dietary behaviours are mostly habitual (Wansink \& Sobal, 2007; Wood et al., 2002) and occur without conscious effort (Kahneman, 2003; Neal et al., 2006). Thus, people are not always aware of the motivation of the choice. By using the eye-tracking tool, we are able to measure the ability of different displays proposed to capture the attention of participants. Specifically, the eye-tracker measures in milliseconds how long an individual look at a specific part of the shelf in this case. The main idea is that the more visible a product or an aggregate are, the higher the probability they will be selected (Buttle, 1984).

Furthermore, the present study wants to enrich the extant literature by considering more options in the experiment. Chernev et al. (2015) in conducting a meta-analysis, collected a series of studies that tried to measure the effects of choice overload. The study pointed out two main limitations: the first is related to the fact that the number of alternatives proposed in different food categories (jams, chocolate, crackers; assorted products) do not exceed 54 options (large assortment). It would appear, then, that what prior research has actually shown is that choice among relatively limited alternatives is more beneficial than no choice at all. However, in the majority of the cases this does not reflect the real assortment found in a store, composed by a greater number of products. Thus, in our experiment, we considered 51 alternatives in the reduced assortment and 73 in the large one, in order to recreate the complexity shoppers face while shopping.

Finally, we tested the effect of choice overload in a realistic setting, developing realistic displays. By looking at the literature, it is clear that researchers asked participants to make a choice between a variety of options without giving a frame for the choice or in contexts other than the display, in front of which the majority of the decisions are made (Chernev et al., 2018).

Given the above considerations, this paper aims to test both cognitive and unconscious reactions of consumers to assortment variety reduction in the pastry category adopting the theory according to which larger assortments have negative consequences on choices and on satisfaction with them (choice overload or overchoice theory). Furthermore, the present work wants to test the hypothesis of overchoice theory in a laboratory setting recreating a real supermarket. This gave also us the possibility to analyse the total sales of the category in the two situations.

\section{Method}

In order to achieve our goal, an experiment, involving 171 participants (mean age 44, 73\% female), was conducted in a laboratory supermarket in Milan to test the reactions in front of a regular pastry display and a reduced assortment one. At the beginning of the study, participants were asked to shop and they were given a shopping list containing the pastry category. Moreover, they were asked to wear eye-tracker glasses during the shopping. Then, at the end of the purchases, they were asked to fill a questionnaire regarding the satisfaction toward the shopping expedition and perceived ease of choice using Likert scales. This approach led us to make participant unaware of the category that we wanted to test in order to avoid biasing their behaviors. Finally, with the eye-tracking tool we have been able to catch the areas on the shelves more attractive and to measure the time spent in front of the displays before the choice. Using SPSS we compare the results obtained in front of the two different shelves and we assessed the significance of the differences found. Spss is short for Statistical Package for the Social Sciences, and it's used by various kinds of researchers for complex statistical data analysis. Statistics included in the base software are descriptive statistics (cross tabulation, frequencies, descriptives), bivariate statistics (means, t-test, ANOVA, correlation, nonparametric tests), prediction for numerical outcomes (linear regression) and prediction for identifying groups (factor analysis, cluster analysis). 


\subsection{Development of the In-Store Stimuli}

For the purpose of the study, we developed two different displays: the first one (traditional display) was built in a way that reflected the arrangement and size of a pastry display usually found in a middle sized supermarket in Italy (800-1000 square meters). Specifically, it was composed by 73 skus and 33 brands. The second one (reduced assortment) presented 51 skus and 22 brands. In order to cut the references, we analysed the one year period sales data of all the stores belonging to the Italian chain that participated in the study and gave the name to the laboratory store. At the end of the analysis of sales and margins, we deleted the least performing brands and products. Pictures of the two displays are presented in Appendix A.

\subsection{Measures}

In order to test the main differences in the behavior of the participants in front of the two stimuli, we analysed the total time spent in front of the display (seconds), the time spent before making the first choice and the total number of products seen while shopping the pastry category. These variables were measured thanks to the use of the eye-tracking tool. Then, at the end of the shopping trip, we asked participants to rate on a 5-points Likert scale the perceived ease of choice and satisfaction with the choice. Furhermore we were able to measure the average price spent on each shopping expedition. Data were analysed using SPSS package.

\section{Results}

\subsection{Recruitment}

All the dara were collected in a 2-week period (starting from $1^{\text {st }}$ October, 2019).

\subsection{Statistics and Data Analysis}

In the Appendix B, the results of the eye-tracking tool are presented. As shown in the heat maps, participants see less products in front of the experimental display (reduced assortment) compared with the traditional one (large assortment). A the same time, people in front of the experimental display focus their attention mostly on products on the top of the shelf following a horizontal pattern, while no clear patterns are found in the traditional display.

For what concerns the time spent in front of the display in the two conditions, the time spent before the first choice, the total number of products seen by partipants, the perceived ease of choice, the satisfaction with the choice and the average price spent, Table 1 shows the results of the chi-square analysis.

Table 1. Output of chi-square analysis

\begin{tabular}{llll}
\hline & TRADITIONAL DISPLAY & EXPERIMENTAL DISPLAY & P-value \\
\hline TIME SPENT IN FRONT OF THE DISPLAY $(\mathrm{sec})$ & 72.02 & 66.35 & $<.05$ \\
TIME SPENT BEFORE THE FIRST CHOICE $(\mathrm{sec})$ & 18.2 & 17.1 & $\mathrm{~ns}$ \\
NUMBER OF PRODUCTS SEEN & 31.46 & 22.62 & $<.05$ \\
& & & $<.10$ \\
PERCEIVED EASE OF CHOICE & 4.01 & 4.35 & $<.10$ \\
SATISFACTION WITH THE CHOICE & 4.34 & 7.73 & $<.10$ \\
AVERAGE PRICE SPENT FOR PASTRY PRODUCTS $(€)$ & 6.68 & 7.12 & \\
\hline
\end{tabular}

The table shows that participants spend less time in front of the reduced assortment display and they take less time to choose the products to buy. At the same time, they see less products, coherently with the results of the heat maps. Furthermore, regarding the cognitive responses, participants experience a greater ease in finding the products that they need in front of the display with fewer options compared to the large one, and they declare they are more satisfied with their choice while shopping in front of the reduced assortment stimulus. Finally, they spend more for the products in front of the display with fewer options.

\section{Discussion and Conclusions}

The present study wanted to measure the effect of choice overload in the pastry category. In doing so we conducted a laboratory experiment where, during a two-week period, two different pastry displays (large assortment and assortment with fewer options) were tested. Specifically, we measured the impact of overchoice on satisfaction with the choice, perceived ease of choice, time spent in front of the display and total number of 
products seen on the shelf before the choice.

The results presented in the previous session, can lead us to conclude that by offering shoppers fewer options it is possible to obtain positive outcomes: giving shoppers fewer options make them more satisfied with the choice and lead them to spend more in order to buy products. These results can help us give Retailers important clues about how to increase shoppers' satisfaction and, consequently, sales.

First of all, by reducing the number of alternatives proposed in the pastry category it is possible to meet the need of the shoppers to save time during the shopping expedition, since it is considered an exhausting activity, and to simplify the choice in an environment rich of stimuli (Bhakat \& Muruganantham, 2013; Donovan, 1994; Inman et al., 2009).

Secondly, we can conclude that display fewer options can lead to an increase in sales. Shoppers, in fact, spend more when they retailers are able to simplify their choice. If retailers offer fewer products they can reduce purchasing cost, warehouse costs, logistic costs (e.g. shelf loading), space management costs and at the same time they can gain more money. This scenario can reshape the relationship between retailers and manufactures as well. Given these results, retailers can have more power during the negotiation process.

\section{References}

Bhakat, R. S., \& Muruganantham, G. (2013). A Review of Impulse Buying Behavior. International Journal of Marketing Studies, 5(3). https://doi.org/10.5539/ijms.v5n3p149

Buttle, F. (1984). Merchandising. European Journal of Marketing, 18(6/7), 104-123. https://doi.org/10.1108/EUM0000000004795

Chernev, A. (2003a). Product assortment and individual decision processes. Journal of Personality and Social Psychology, 85(1), 151-162. https://doi.org/10.1037/0022-3514.85.1.151

Chernev, A. (2003b). When More Is Less and Less Is More: The Role of Ideal Point Availability and Assortment in Consumer Choice. Journal of Consumer Research, 30(2), 170-183. https://doi.org/10.1086/376808

Chernev, A., \& Hamilton, R. (2009). Assortment size and option attractiveness in consumer choice among retailers. Journal of Marketing Research, 46(3), 410-420.

Chernev, A., Böckenholt, U., \& Goodman, J. (2015). Choice overload: A conceptual review and meta-analysis. Journal of Consumer Psychology, 25(2), 333-358.

Crowne, D. P., \& Marlowe, D. (2011). Marlowe-Crowne Social Desirability Scale [Data set]. American Psychological Association. https://doi.org/10.1037/t05257-000

Dennis, C., King, T., \& Martenson, R. (2007). Corporate brand image, satisfaction and store loyalty. International Journal of Retail \& Distribution Management.

Donovan, R. (1994). Store atmosphere and purchasing behavior. Journal of Retailing, 70(3), 283-294. https://doi.org/10.1016/0022-4359(94)90037-X

Fasolo, B., McClelland, G. H., \& Todd, P. M. (2007). Escaping the tyranny of choice: when fewer attributes make choice easier. Marketing Theory, 7(1), 13-26. https://doi.org/10.1177/1470593107073842

Gourville, J. T., \& Soman, D. (2005). Overchoice and Assortment Type: When and Why Variety Backfires. Marketing Science, 24(3), 382-395. https://doi.org/10.1287/mksc.1040.0109

Harrison, D. A., McLaughlin, M. E., \& Coalter, T. M. (1996). Context, Cognition, and Common Method Variance: Psychometric and Verbal Protocol Evidence. Organizational Behavior and Human Decision Processes, 68(3), 246-261. https://doi.org/10.1006/obhd.1996.0103

Inman, J. J., Winer, R. S., \& Ferraro, R. (2009). The Interplay Among Category Characteristics, Customer Characteristics, and Customer Activities on In-Store Decision Making. Journal of Marketing, 73(5), 19-29. https://doi.org/10.1509/jmkg.73.5.19

Iyengar, S. S., \& Lepper, M. R. (2000). When choice is demotivating: Can one desire too much of a good thing? Journal of Personality and Social Psychology, 79(6), 995-1006. https://doi.org/10.1037/0022-3514.79.6.995

Iyengar, S. S., \& Lepper, M. R. (2006). When Choice Is Demotivating: Can One Desire Too Much of a Good Thing? In S. Lichtenstein \& P. Slovic (Eds.), The Construction of Preference (pp. 300-322). Cambridge University Press. https://doi.org/10.1017/CBO9780511618031.017

Kahneman, D. (2003). Maps of Bounded Rationality: Psychology for Behavioral Economics. American 
Economic Review, 93(5), 1449-1475. https://doi.org/10.1257/000282803322655392

Mantrala, M. K., Levy, M., Kahn, B. E., Fox, E. J., Gaidarev, P., Dankworth, B., \& Shah, D. (2009). Why is assortment planning so difficult for retailers? A framework and research agenda. Journal of Retailing, 85(1), 71-83.

Martenson, R. (2007). Corporate brand image, satisfaction and store loyalty: A study of the store as a brand, store brands and manufacturer brands. International Journal of Retail \& Distribution Management, 35(7), 544-555. https://doi.org/10.1108/09590550710755921

Neal, D. T., Wood, W., \& Quinn, J. M. (2006). Habits-A Repeat Performance. Current Directions in Psychological Science, 15(4), 198-202. https://doi.org/10.1111/j.1467-8721.2006.00435.x

Nunkoosing, K. (2005). The Problems With Interviews. Qualitative Health Research, 15(5), 698-706. https://doi.org/10.1177/1049732304273903

Papies, E. K. (2016). Health goal priming as a situated intervention tool: how to benefit from nonconscious motivational routes to health behaviour. Health Psychology Review, 10(4), 408-424. https://doi.org/10.1080/17437199.2016.1183506

Salmon, S. J., De Vet, E., Adriaanse, M. A., Fennis, B. M., Veltkamp, M., \& De Ridder, D. T. D. (2015). Social proof in the supermarket: Promoting healthy choices under low self-control conditions. Food Quality and Preference, 45, 113-120. https://doi.org/10.1016/j.foodqual.2015.06.004

Scheibehenne, B., Greifeneder, R., \& Todd, P. M. (2009). What moderates the too-much-choice effect? Psychology and Marketing, 26(3), 229-253. https://doi.org/10.1002/mar.20271

Scheibehenne, B., Greifeneder, R., \& Todd, P. M. (2010). Can There Ever Be Too Many Options? A Meta-Analytic Review of Choice Overload. Journal of Consumer Research, 37(3), 409-425. https://doi.org/10.1086/651235

Self-Report Measures. (2011). In SpringerReference. Springer-Verlag. https://doi.org/10.1007/SpringerReference_183983

Simon, H. A. (1955). A behavioral model of rational choice. Quarterly Journal of Economics, 59, 99-118.

Wansink, B. (2012). From Mindless Eating to Mindlessly Eating Better: (519682015-001) [Data set]. American Psychological Association. https://doi.org/10.1037/e519682015-001

Wansink, B., \& Sobal, J. (2007). Mindless Eating: The 200 Daily Food Decisions We Overlook. Environment and Behavior, 39(1), 106-123. https://doi.org/10.1177/0013916506295573

Wood, W., Quinn, J. M., \& Kashy, D. A. (2002). Habits in everyday life: Thought, emotion, and action. Journal of Personality and Social Psychology, 83(6), 1281-1297. https://doi.org/10.1037//0022-3514.83.6.1281 


\section{Appendix A}

\section{The traditional display}

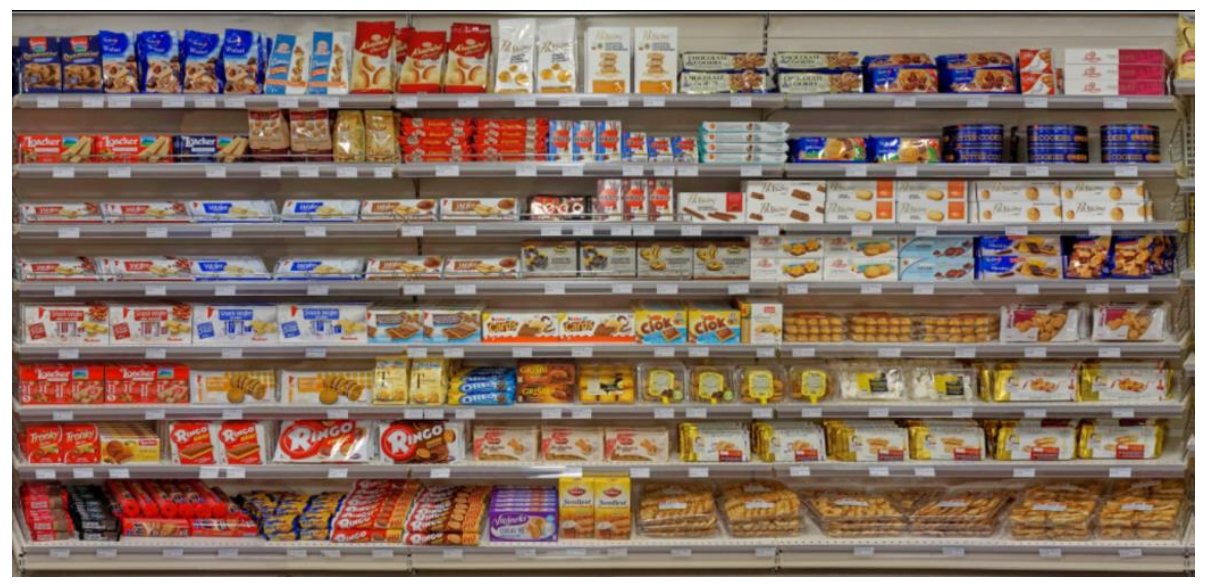

The experimental display (reduced assortment)

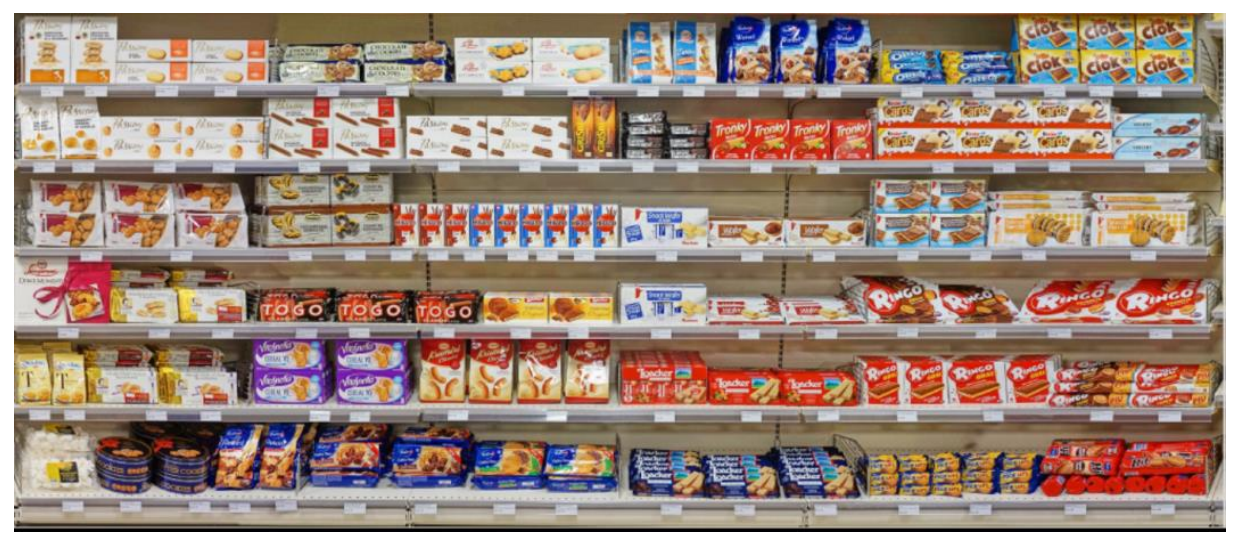

\section{Appendix B}

The results of the eye-tracker.

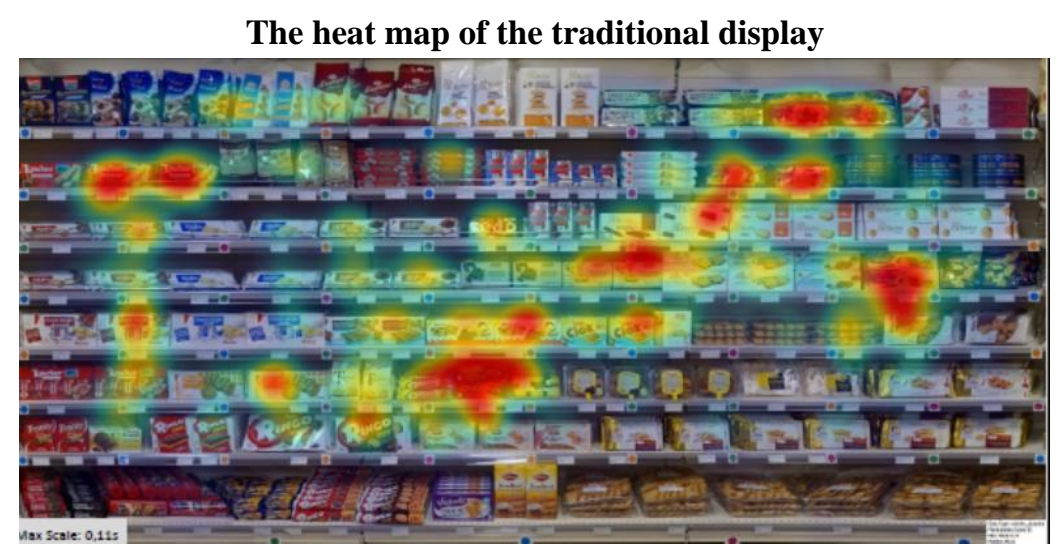




\section{The heat map of the experimental display}

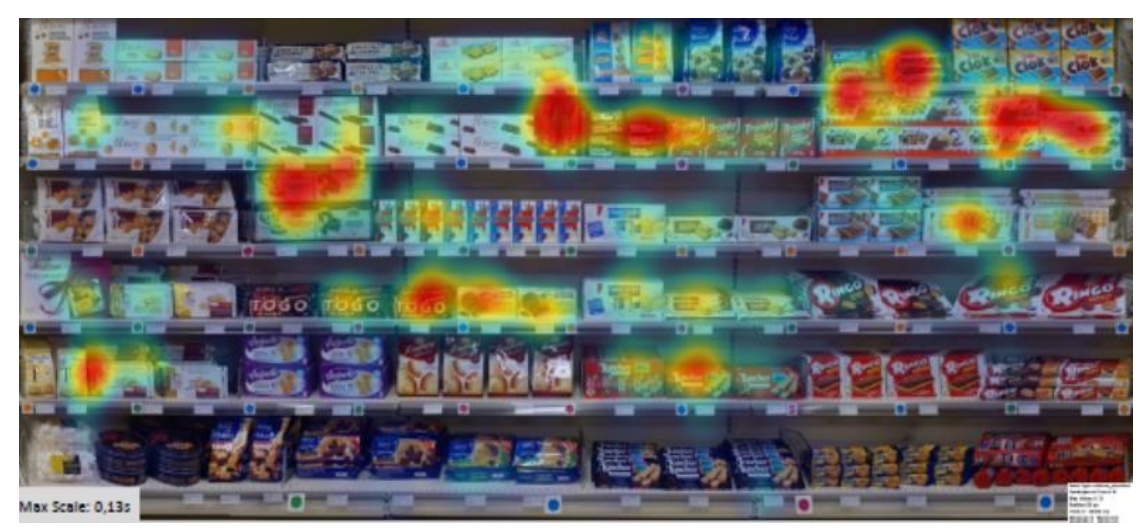

\section{Copyrights}

Copyright for this article is retained by the author(s), with first publication rights granted to the journal.

This is an open-access article distributed under the terms and conditions of the Creative Commons Attribution license (http://creativecommons.org/licenses/by/4.0/). 